\title{
Convenient and worth the price? Identifying early users and predicting future use of book streaming services
}

Convergence: The International Journal of Research into New Media Technologies 2021, Vol. 0(0) I-18

(c) The Author(s) 2021

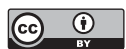

Article reuse guidelines: sagepub.com/journals-permissions DOI: $10.1177 / 13548565211057516$ journals.sagepub.com/home/con @SAGE

\author{
Linn-Birgit Kristensen 10 and Marika Lüders \\ Department of Communication and Culture, BI Norwegian Business School, Oslo, Norway; \\ Department of Media and Communication, University of Oslo, Oslo, Norway
}

\begin{abstract}
The printed book has been resilient to change, and the adoption of e-books has been slow. In this context, few studies have addressed a potential turn to streaming services for books. This paper examines the adoption of book streaming in the Norwegian market, where the market-leaders Storytel and Fabel report rapid increases in number of subscribers. We examine who these early adopters are, and what may predict future use of streaming services among non-users. Theoretically, the study is situated within the fields of innovation diffusion and technology acceptance. The study is based on a cross-sectional online survey with a representative sample of the Norwegian population. Results show that users are younger and more educated, and that book streaming is more popular among women than men. The audiobook format allows for flexible ways of consuming books, complementing rather than replacing the printed book. For non-users, results show that convenience value and price value predict behavioural intention to use book streaming services. While emotional attachment to printed books has been found to act as a barrier for adoption of e-books, its negative effect on behavioural intention for book streaming services is only modest.
\end{abstract}

\section{Keywords}

Diffusion of innovations, technology acceptance, digital reading, streaming services, factor analysis

\section{Introduction}

Streaming services have caused significant changes in how audiences consume media content. Music streaming services have largely supplanted purchases of music in physical and digital formats

\section{Corresponding author:}

Linn-Birgit Kristensen, Department of Communication and Culture, BI Norwegian Business School, Nydalsveien 37, Oslo 0442, Norway, Linn-birgit.k.kristensen@bi.no. 
(Hampton-Sosa, 2017; Sinclair and Tinson, 2017). Likewise, television streaming services have become increasingly popular (Tefertiller, 2019). A similar turn to streaming appears to be happening also with how people access and read books. It should be noted that printed books and traditional ways of accessing, borrowing and purchasing books have been quite resilient to change, at least when compared to most other types of media content. E-books were expected to cause major disruptions in the traditional book industry (Loebbecke, 2010), but adoption of e-books has been slow, and most readers prefer printed books (Bergström and Höglund, 2020). Streaming services for books, however, offer a reading experience that differ from printed books and e-books, and ondemand access to audiobooks represents an experiential shift in how and when books are read (Wallin and Nolin, 2020). This could imply that audiobook subscription services do not primarily compete with printed books and that the growth of these services might continue beyond the slower adoption rates of e-books.

This article investigates the adoption of book streaming services in Norway, where marketleaders Storytel and Fabel report substantial increases in number of subscribers (Bergo, 2018; Hegnar, 2021). The business models of Storytel and Fabel are similar to Spotify and Netflix, with a monthly subscription fee that grants access to audiobooks and e-books. Storytel Norway is coowned by the Norwegian publisher Cappelen-Damm and Storytel AB (the Swedish branch), while Fabel is owned by the oldest publisher for audiobooks in Norway, Lydbokforlaget (owned by two of the largest publishers in Norway: Gyldendal and Aschehoug). Storytel was launched in late 2014 and has over 250,000 titles available on their platform, ranging from new publications to old classics in all genres. The monthly price for Storytel ranges from 189 Norwegian kroner (NOK) (about \$22) to 309 NOK (about \$36) depending on how many profiles on one account the subscriber wants. Storytel offers some books as both e-books and audiobooks and the opportunity to swap between the two formats with the service keeping track of reading-progress. However, most subscribers prefer the audiobook format. Fabel was launched in spring 2017. The company does not disclose the full number of book titles available, but offer audiobooks (only) across a wide variety of genres. The monthly price for Fabel is 179 NOK (about \$21). At the time of writing, Fabel does not offer differentiated subscriptions with multi-profile subscription-accounts. Due to different owners, Storytel and Fabel currently have different selections of books available for streaming. Principally, subscribers cannot find books published by Cappelen-Damm at Fabel, or books published by Gyldendal or Aschehoug at Storytel. The exception is how both providers may include the same titles from other publishers.

In Norway (5.3 million inhabitants), book streaming represents the fastest growing part in an otherwise declining book market, with an increase from two million listening sessions in 2017 to 5.2 million listening sessions in 2019. This represents an increase in turnover from streaming from 113 million NOK in 2017 to 263 million NOK in 2019 (Den Norske Forleggerforening, 2020). While turnover from streaming is still minor compared to sales of printed books, these services may have the potential to disrupt the way people, and the younger segments of the population in particular, consume books (Kristensen and Solvoll, 2019). In this article, we study who book-streamers are and to what extent we can expect that the number of book-streamers will continue to rise. Accordingly, we first pose the exploratory research question who is the early adopters of book streaming services, and what characterises their use and experiences? Next, we enquire what may predict future use of book streaming services among current non-users?

We proceed with the theoretical framework and outlining the research model to be tested for our second research question. Next, method and measurements are accounted for before presenting the results from a cross-sectional survey conducted among a representative sample of the Norwegian population in 2018. Finally, results are discussed. 


\section{Theoretical framework and hypotheses}

We might assume that the adoption of streaming services for books has reached the stage of what Rogers (2003) terms the time period during which diffusion 'takes off': innovators and early adopters have started to use these types of services. Given the novelty of book streaming services and the increase in number of subscribers over the last few years, it is plausible to consider current book-streamers as early users. Rogers depicts earlier adopters as more educated and to have a higher social status than later adopters. He finds little evidence that earlier adopters are different from later adopters in age, but the literature on use of online services report age as negatively associated with online skills (Hargittai, 2002; Hargittai, et al., 2019; Van Deursen and Van Dijk, 2011), and age has been found to be the most prominent socio-demographic variable relating to amount and types of Internet usage (Dutton and Reisdorf, 2019; Van Deursen and Van Dijk, 2014). While we do not propose specific hypotheses to be tested for our first research question, we might expect that the early adopters of book streaming services will be younger, more educated and have higher income compared to non-users. How gender plays out as a differentiator is more ambiguous: men tend to be earlier adopters of new technologies, yet women are more frequent readers (Bergström and Höglund, 2020).

\section{Technology acceptance: predicting behavioural intention}

Both research questions are examined from the perspective of technology acceptance and subsequent refinements of the theory. With regard to early adopters (RQ1), technology acceptance is used to examine what characterises their experiences. Technology acceptance studies hence address Rogers' call for understanding why people adopt an innovation (Rogers, 2003: 114). With regard to predicting intention to start using book streaming services (RQ2), we rely on technology acceptance theory to build our research model.

Technology acceptance models were developed to identify how perceived ease of use and perceived usefulness predict acceptance of workplace technologies (Davis, 1989). Numerous additional constructs have since been added, such as social influence (Venkatesh et al., 2003), perceived enjoyment (Davis et al., 1992), and cognitive function (Taherdoost, 2018). These extensions also reflect efforts to apply the model from organizational context to consumer technologies (Van der Heijden, 2004). The unified theory of acceptance and use of technology (UTAUT) (Venkatesh et al., 2003) and later extensions (Venkatesh et al., 2012) represent the most comprehensive efforts to explain variance in behavioural intention and use of technology. The present study has not been designed to include all UTAUT-constructs, and we focus on the most resilient and relevant constructs for consumer technologies and as adapted to what may predict future intention to use streaming services for books: performance expectancy, effort expectancy, social influence, and price value. We additionally include emotional attachment to printed books as a construct negatively predicting behavioural intention.

Performance expectancy re-conceptualized as convenience value. Performance expectancy is defined as 'the degree to which using a technology will provide benefits to consumers in performing certain activities (Venkatesh et al., 2012: 159). In adapting this construct to the domain of streaming services, we re-conceptualize performance expectancy as the perceived convenience value of such services. Convenience value in a self-service context has been defined as 'the perceived time and effort required in finding and facilitating the use of a self-service technology' (Collier et al., 2014: 63) and hence aligns with the conceptual definition of performance expectancy. Collier et al. (2014) found that convenience perceptions had a significant association with hedonic and utilitarian value. 
People's reading attitudes have been found to reflect hedonic (enjoyment, escape) and utilitarian (development, utility) functions (Stokmans, 1999), yet in this study, we follow Oyedele and Simpson (2018) largely utilitarian-oriented operationalization of the convenience value of what they term entertainment streaming applications (ESAs). The construct reflects the typical marketing rhetoric of streaming services as enabling access to any content anytime and anywhere, with items such as 'I value the ability to use ESAs to watch or listen to what I want while away from home' (Oyedele and Simpson, 2018: 300). Convenience value also reflects Wallin and Nolin (2020) account of the shifting timespace of reading associated with book streaming services. Our interest is to what extent perceived convenience value might explain intentions to start using streaming services for books. Hence, H1: Perceived convenience value is positively related to behavioural intention.

Effort expectancy. In consumer-contexts, the degree to which systems are perceived as easy to use can be considered particularly important. Unlike work-related systems where completing a task is the primary objective, consumers are likely less willing to accept hurdles and complexities in interactions with systems (Van der Heijden, 2004). Whereas, the user acceptance literature differs in terming the effort-construct ease of use and effort expectancy, the construct has retained the same types of measurement items (c.f. Davis, 1989; Venkatesh et al., 2003). Given the robustness of the construct and the its recurring importance for explaining behavioural intention, we include effort expectancy as a potentially central construct, conceptualized as the degree to which people perceive that using a technology is free from substantial effort (Venkatesh et al., 2003). Thus, H2: Perceived effort expectancy is positively related to behavioural intention.

Social influence. A recurring thread in research on behavioural intention is the importance of social norms and influence: social pressure to perform (or not to perform) a certain type of behaviour matters (Ajzen, 1991). In the user acceptance literature, the importance of peers is conceptualized as social influence, referring to the extent to which consumers perceive friends, acquaintances and family believe they should use a certain technology (Venkatesh et al., 2003, 2012). Social influence is also central in Rogers (2003) emphasis on communication flows and the importance of earlier adopters in diffusion of innovations. Applied to the context of streaming services for books, we hence expect perceptions of important others using these systems to be of importance for future intentions to stream books. Thus, H3: Social influence is positively related to behavioural intention.

Price value. User acceptance studies were initially conducted in organizational settings, that is, in use-contexts where employees would not bear the monetary costs of use. In consumer-technology contexts, costs of use must be included as a potential antecedent to behavioural intention. (Venkatesh et al. 2012: 161) define price value as 'consumers' cognitive tradeoff between the perceived benefits of the applications and the monetary costs for using them'. If benefits of use are perceived as greater than the monetary cost, price value is positive and expected to predict behavioural intention. Thus, H4: Perceived price value is positively related to behavioural intention.

Emotional attachment to printed books. Several studies have examined use and non-use of ebooks and e-readers, often applying a user acceptance framework (see, e.g. Antón et al., 2017; Lee, 2013; Read et al., 2011; Torres et al., 2014). From these studies, emotional attachment to printed books appears to be an important barrier towards adoption of e-books. Collections of printed books accrued over time and different phases of life act as signals of self-identity and social status, and reading printed books is a sensory experience that digitized books cannot easily replace or remediate. Helm et al. (2018) rely on a focus-group study and find that experiences of psychological ownership increase with multisensory engagement. E-books were found inferior in this context and hence precluded development of attachment (Helm et al., 2018). Survey-based studies similarly suggest that emotions negatively affect intentions to adopt e-reader technology and use of e-books 
(Antón et al., 2017; Loebbecke, 2010; Read et al., 2011; Shim et al., 2016). We expect a similar effect for book streaming services, hence H5: Emotional attachment to printed books is negatively related to behavioural intention.

Demographic variables. In this study, we test for the main effects of age and gender, but we refrain from proposing hypotheses for how these demographic variables are associated with behavioural intention. Studies that have applied a user-acceptance framework to investigate intentions to use e-books tend not to include demographic variables (e.g. Antón et al., 2017; Lee, 2013; Read et al., 2011; Torres et al., 2014; Williams et al., 2014), which means we have limited indication for proposing how demographic variables impact intention to start using book streaming services.

\section{Method and data}

This study is based on a representative online population survey of the Norwegian population in 2018 with 1511 respondents. Post-stratification weights (minimum=0.415; maximum=2.536) allow the sample to match the composition of the Norwegian population on age, gender and education. 199 respondents (13\%) reported to use book streaming services. The remaining 1312 respondents were included in the subsample to test the hypotheses. Demographic variables remain relatively stable between the full sample and the subsample of non-users (see Table 1).

Regression models were estimated with both the unweighted and the weighted data, and no substantial differences were found. Therefore, results from unweighted analyses are reported, as these are more efficient and the estimated standard errors will be minimized (Winship and Radbill, 1994).

\section{Measurements}

Respondents were asked to report approximately how many minutes they had spent reading printed books and reading e-books the day before answering the survey. Book-streamers were additionally asked to report approximately how many minutes they had spent streaming books the day before answering the survey. The questionnaire introduced questions about streaming services for books with a brief explanation of how these services function and comparing these to other media streaming services.

Table 2 includes items (in condensed form compared to the questionnaire) for measured constructs. For all of these items, respondents indicated whether they agreed with statements on a 5point Likert-scale ranging from 1 (completely disagree) to 5 (completely agree). The constructs convenience value, effort expectancy, social influence, price value and behavioural intention were adapted from prior research (Ajzen, 2002; Oyedele and Simpson, 2018; Venkatesh et al., 2012). Convenience value items reflect how book streaming services are used for listening rather than reading books. For non-users, items for convenience value and effort expectancy were phrased hypothetically (e.g. 'I would find these services easy to use'). The construct emotional attachment to printed books is adapted from research on the e-book literature (Antón et al., 2017; Bergström and Höglund, 2020; Read et al., 2011).

\section{Factor analysis}

The items were subjected to a principal component analysis with oblimin rotation. Factors that loaded with an eigenvalue of 1 or greater and had at least three loadings using a 60-40 rule were retained. Items that loaded on each factor were summed and averaged. The KMO value is 0.885 , 
Table I. Demographics full sample, users and non-users of book streaming services (weighted).

\begin{tabular}{|c|c|c|c|}
\hline & Full sample $(n=5 \mathrm{II})$ & Users $(n=199)$ & Non-users $(n=|3| 2)$ \\
\hline \multicolumn{4}{|l|}{ Gender, \% } \\
\hline Male & 51 & 41 & 52 \\
\hline Female & 49 & 60 & 48 \\
\hline \multicolumn{4}{|l|}{ Age, $\%$} \\
\hline Mean age/SD. & $47 / 17.5$ & $40.4 / 15.5$ & $48.3 / 17.6$ \\
\hline Below 30 years & 21 & 31 & 19 \\
\hline $30-49$ & 26 & 32 & 25 \\
\hline $50-59$ & 26 & 25 & 26 \\
\hline 60 years or older & 28 & 13 & 30 \\
\hline \multicolumn{4}{|l|}{ Education, \% } \\
\hline Primary school & 9 & 2 & 10 \\
\hline Upper secondary school & 58 & 59 & 58 \\
\hline Higher education $<4$ years & 19 & 21 & 19 \\
\hline Higher education 4 years $\geq$ & 14 & 18 & 13 \\
\hline \multicolumn{4}{|l|}{ Income before tax, \% } \\
\hline Less than 299999 & 23 & 25 & 23 \\
\hline $300000-499999$ & 35 & 30 & 36 \\
\hline $500000-699999$ & 21 & 22 & 20 \\
\hline 700000 or more & 9 & 11 & 9 \\
\hline Do not want to answer & 12 & 13 & 12 \\
\hline
\end{tabular}

Some variables do not add to $100 \%$ due to rounding. Income in NOK (I NOK $\approx 0.12$ USD).

which indicates adequate sampling and that the factor analysis yields distinct and reliable factors. The resultant factors explained $76.23 \%$ of the total variance after rotation. Cronbach's alpha for all constructs were well above the recommended value of 0.7 (see Table 2 for details).

The factor analysis shows that effort expectancy loads on the same factor as convenience value. Inspecting the items used to measure these two constructs, effort expectancy items can be considered to be about the convenience of book streaming services. In the subsequent analysis, these items are included in the convenience value construct. $\mathrm{H} 2$ can hence not be tested separately. Likewise, social influence items and behavioural intention items load as one factor. We included the two social influence items with loadings over 0.60 in our summed and averaged behavioural intention construct, implying $\mathrm{H} 3$ cannot be tested.

\section{Results}

Next, we present findings related to our first research question of who early adopters of book streaming services are. In this part of the analysis, we compare users to non-users. We then present the results pertaining to our second research question of what may predict future use of book streaming services among current non-users.

\section{Early adopters of book streaming services}

In our first research question, we asked who earlier adopters of book streaming services are, and what characterises their use and experience. We address this question by examining if there are 
demographic differences between users and non-users; by examining book-affinities in terms of time reading books in different formats; and by examining how users and non-users compare on predictive variables and behavioural intention.

Book-streamers are younger $(\mathrm{M}=40.3, \mathrm{SE}=1.1)$ than non-users $(\mathrm{M}=48.3, \mathrm{SE}=0.49)$. This difference, $7.94,95 \%$ CI $[5.57,10.30]$ is significant, $\mathrm{t}(282.28)=6.6, p<0.0005 .11 \%$ of the male respondents and $16 \%$ of female respondents report to use book streaming services. This association is significant, $\mathrm{X}^{2}(1)=8.257, p<0.05$. Three per cent of those with primary school education report to use book streaming services compared to $13 \%$ for those with upper secondary school, $14 \%$ of those with higher education less than 4 years and $18 \%$ of those with higher education 4 years or more. This association is significant, $\mathrm{X}^{2}(3)=15.561 p<0.05$. Differences between users and nonusers in terms of income were not significant.

Next, we examine whether book streaming users tend to spend more time reading and listening to books. The mean number of minutes streaming books the day before answering the survey among book-streamers is $30 \mathrm{~min}(\mathrm{SD}=67)$. The large standard deviation relative to the mean reflects that the mean is a poor fit of the data, and $62 \%$ of book streaming users report to have streamed books for $0 \mathrm{~min}$ the day before answering the survey. Highly skewed distributions characterize all formats of consuming books for both book-streamers and non-users, and most respondents have not spent time reading books (excluding reading for studies/work) the day before answering the survey. However, comparing the mean number of minutes between users and non-users of book streaming services indicates that book-streamers have not abandoned other formats of book-consumption. Bookstreamers report to have read printed books for an average of $16.4 \mathrm{~min}(\mathrm{SD}=35.8, \mathrm{SE}=2.6)$, compared an average of $21 \mathrm{~min}$ for non-users $(\mathrm{SD}=46.2, \mathrm{SE}=1.3)$. This difference, $4.5,95 \% \mathrm{CI}$ $[-1.08,10.16]$ is not significant, $t(305.3)=1.58, p>0.1$. Book-streamers report to have read ebooks for an average of $12.1 \mathrm{~min}(\mathrm{SD}=37.05, \mathrm{SE}=2.65)$, compared to $3.5 \mathrm{~min}$ for non-users $(\mathrm{SD}=$ $27.5, \mathrm{SE}=0.77)$. This difference, $-8.59,95 \% \mathrm{CI}[-14.03,-3.15]$ is significant, $t(228)=-3.11, p<$ 0.005 .

Comparing book-streamers and non-users with regard to responses on items measuring our hypothesized predictive constructs and behavioural intentions indicates marked differences between these two groups of respondents (Figures 1 to 4). All figures show the percentage share within each group who agreed or completely agreed with the statements. For convenience value items (Figure 1), book-streamers are more inclined to agree with the statements, and particularly so for statements pertaining to the flexibility of these services, as well as the actual experience of listening to books. These statements all point to the experiential differences between reading and listening to books and relatively well appear to capture the appeal of audiobooks subscription services. It is noteworthy that only $66 \%$ of book streaming users agree that it is easy to find the books they want to read/listen to. This may relate to potential usability-issues, but perhaps just as likely, if not more, to users not finding the particular book they want to read/listen to, as different services offer different selections of books.

Figure 2 includes the items used to measure emotional attachment to printed books, and suggest that book-streamers are less attached to the paper-format and the sensory experience of reading. Yet, a substantial share of users agrees with the statements, and compared to convenience value items, there are less marked differences between users and non-users. Combined with the above reported mean number of minutes consuming books in other formats suggest that for users, reading printed books and listening to digital books is not an either/or option.

With regard to price value (Figure 3), less than half of book streaming users agree or completely agree with the statements measuring the experienced price value of book streaming services. It should be noted that users did not tend to disagree with the statements; between 32 and 35\% of users 

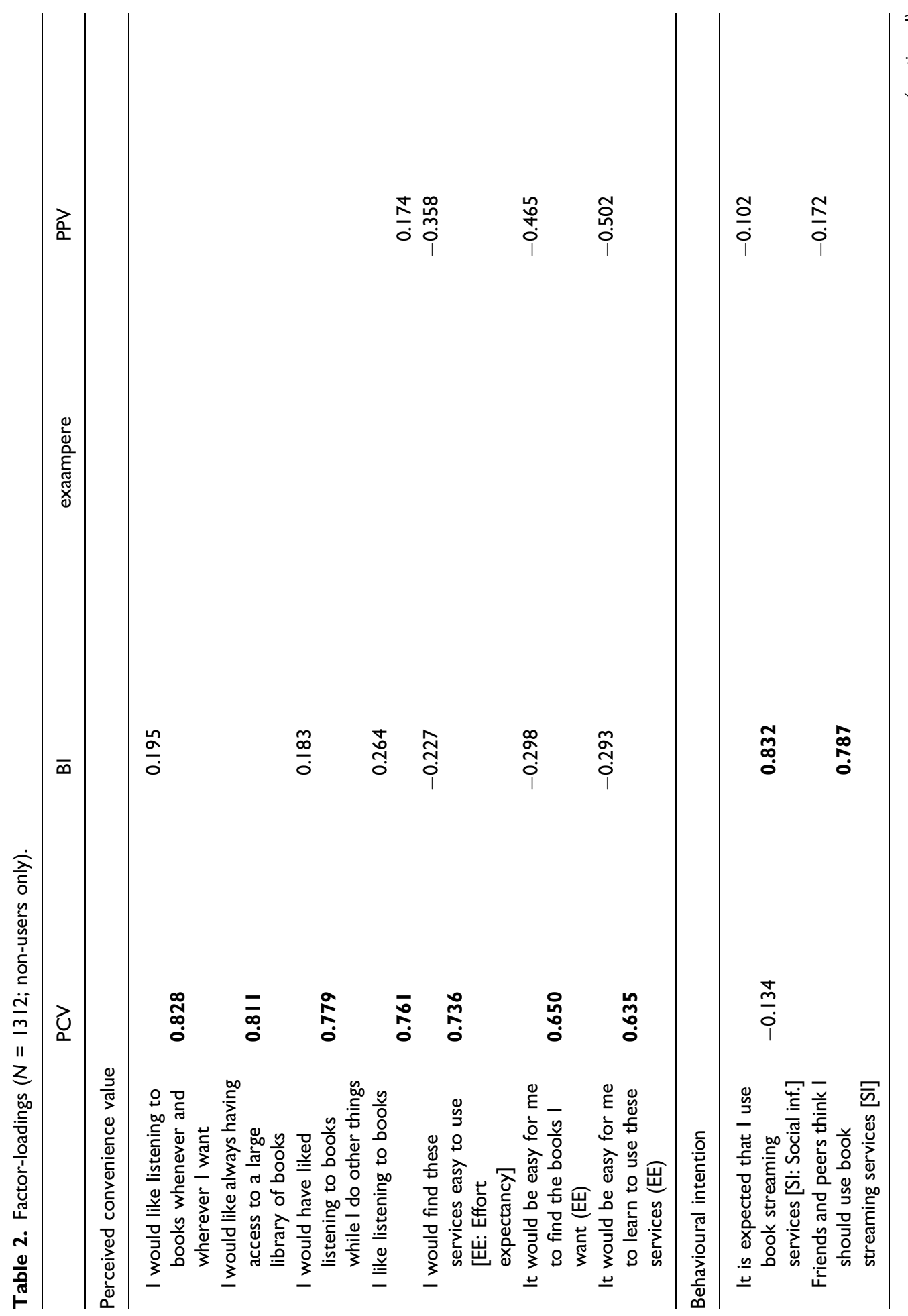


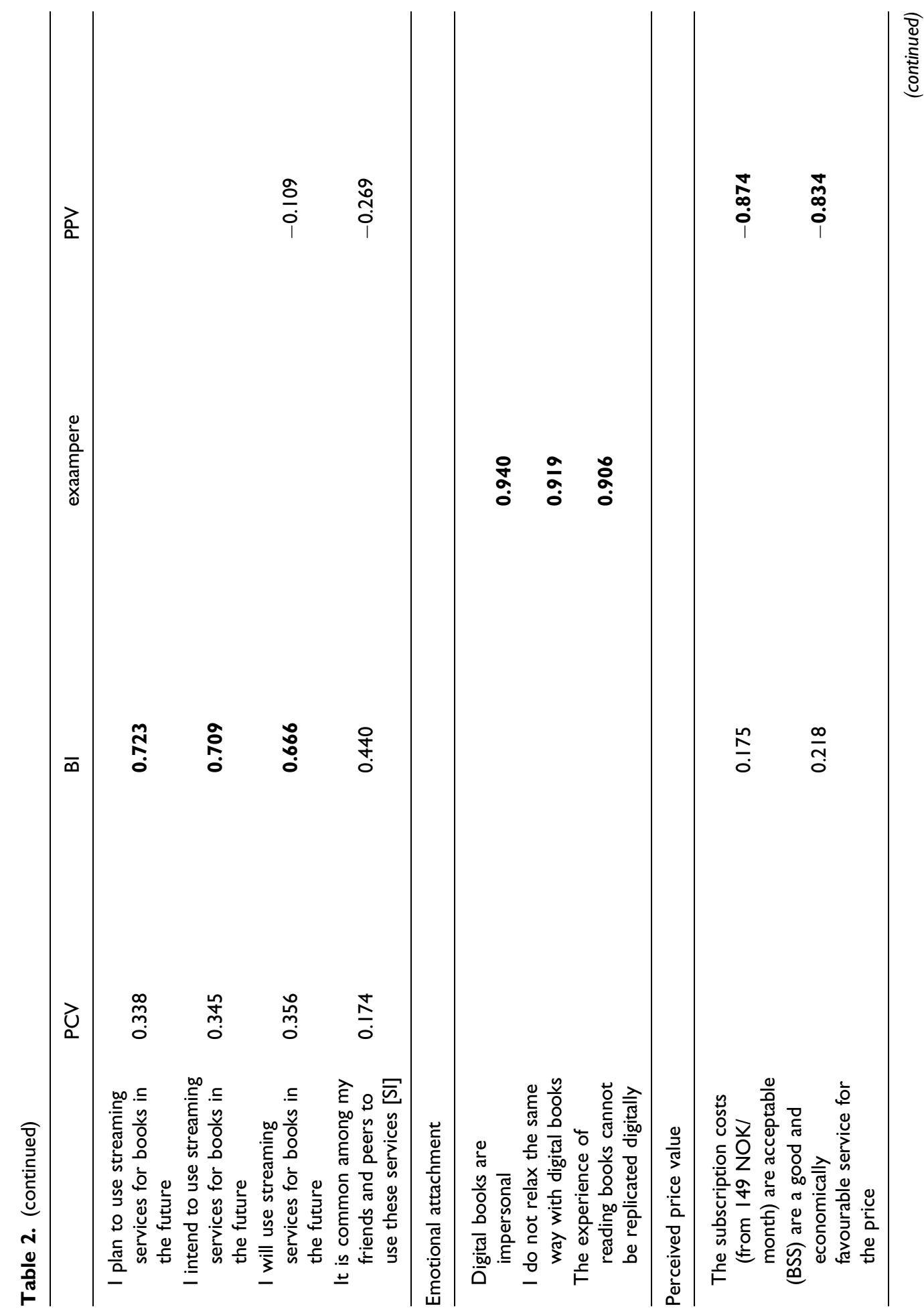




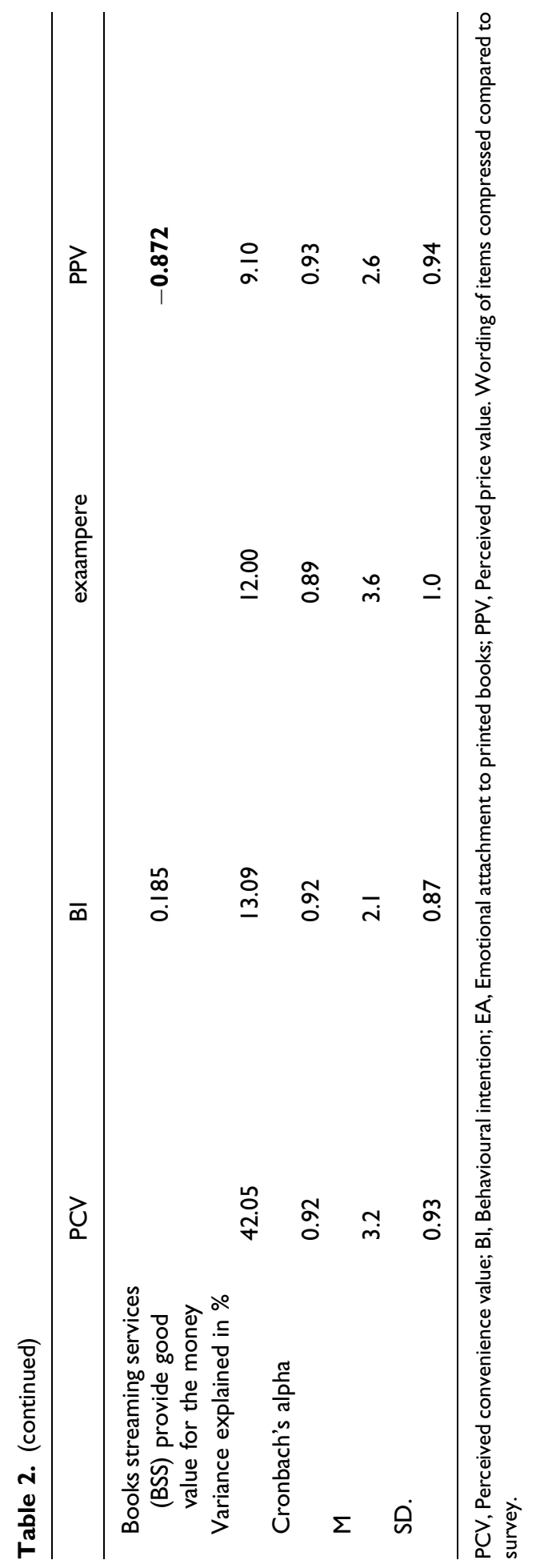




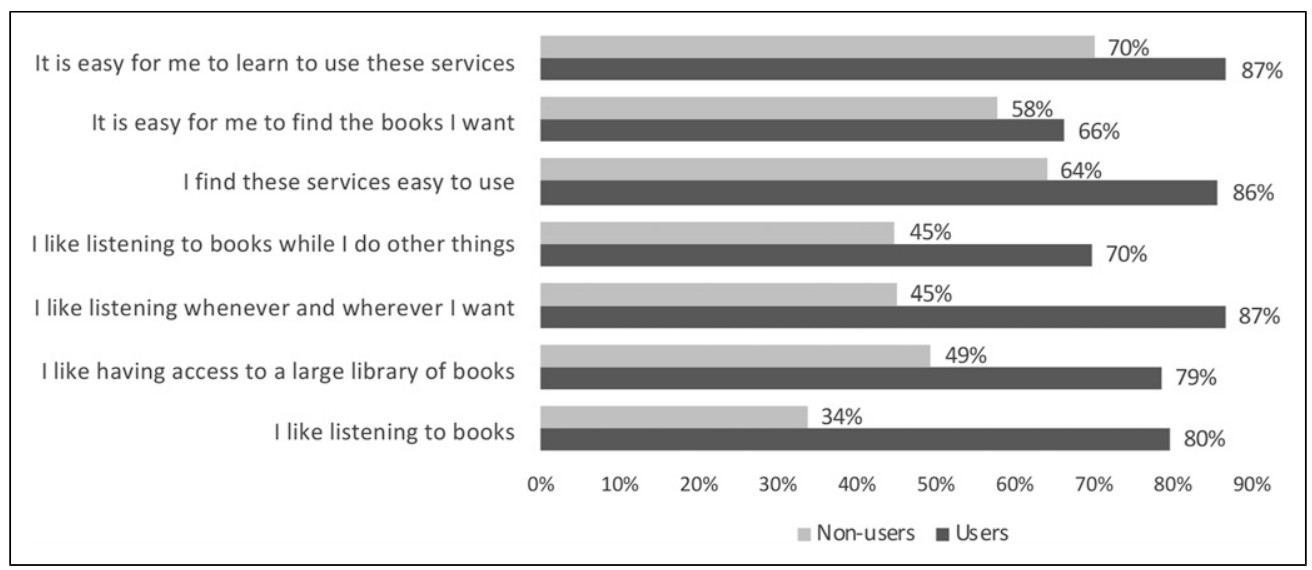

Figure I. Convenience value for users and non-users. The figure shows the percentage share that agrees and completely agrees. Wording of items differed for non-users and users. Items for non-users were phrased as 'I would have liked listening to books while I do other things'.

chose the 'neither disagree nor agree' for these three items. Still, the relatively low shares of users agreeing with the price value statements reflect that even among users, whether these services are worth the price is questioned: the tradeoff between what these services offer and the monetary costs of using them does not necessarily result is a positive gain. These findings may also reflect how book streaming services in the Norwegian market are priced higher than what consumers are accustomed to with music and television streaming services.

Users of book streaming services differ most markedly from non-users on items used to measure behavioural intention (Figure 4). About three quarters of the book-streamers see themselves as book-streamers also in the future. On the two social influence items, the differences between users and non-users are less substantial, and likely reflect the limited adoption of book streaming services in the market.

In the next part of the analysis, we will move to the second research question of what may predict future use of book streaming services among non-users. Before we do so, note that the share of nonusers agreeing with the behavioural intention items is very low. If we were to assess the potentials for book streaming services to reach a substantial share of the population in Norway, these low percentages of non-users agreeing with these statements suggest quite limited growth. Among nonusers, $24-30 \%$ are undecided on the first three statements included in Figure 4, and these non-users may at the outset hence be considered as potentially part of a future market for these services. But, what then, may predict whether non-users intend to start using book streaming services?

The correlations amongst the predictor variables (age, gender, perceived convenience value, perceived price value, emotional attachment to printed books) included in the study were examined and are included in Table 3. Variance inflation factor values were all below 10, and all significant correlations between predictors are weak to moderate ranging between $r=0.063$ ( $p<$ $0.05)$ and $r=0.349(p<0.001)$. This indicates that multicollinearity is unlikely to be a problem. Except for gender, all predictor variables are significantly correlated with behavioural intention. The remaining four predictors are thus included in the hierarchical regression analyses with behavioural intention as the outcome variable. The correlations between these four predictor variables and behavioural intention are all weak to moderately strong, ranging from $r=-0.098(p$ $<0.005)$ to $r=0.448(p<0.001)$. 


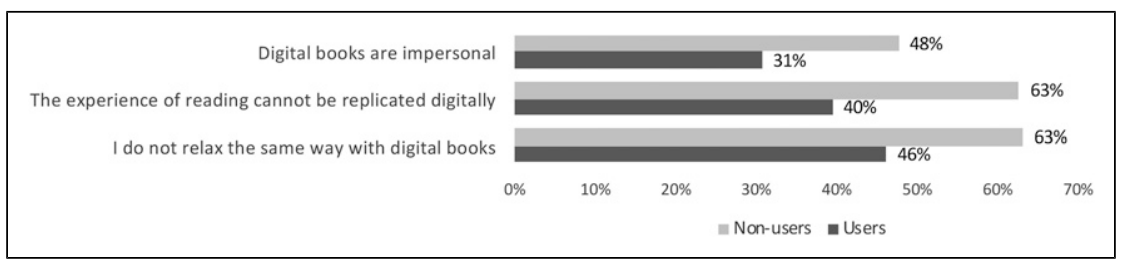

Figure 2. Emotional attachment to printed books for users and non-users. The figure shows the percentage share that agrees and completely agrees.

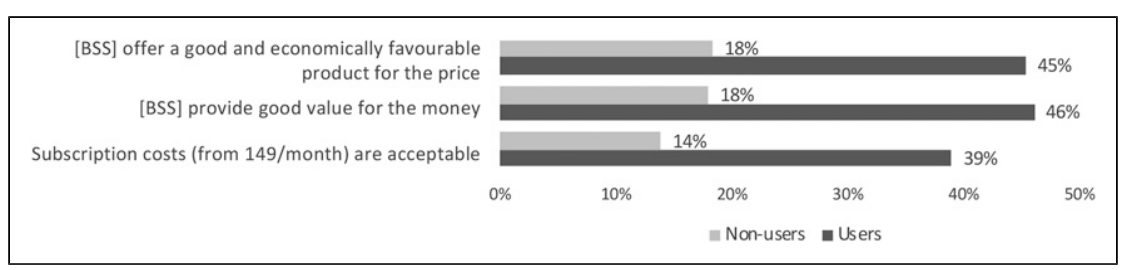

Figure 3. Price value for users and non-users. The figure shows the percentage share that agrees and completely agrees. Book streaming services shortened to BSS in figure, but not in the survey.

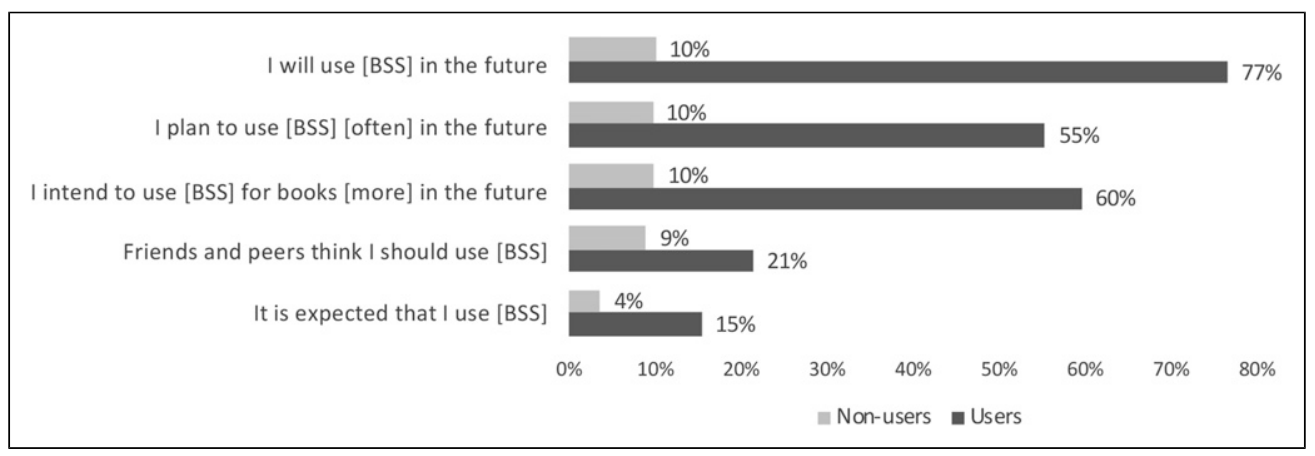

Figure 4. Behavioural intention for users and non-users. The figure shows the percentage share that agrees and completely agrees. Wording of items differed between users and non-users as indicated by square brackets. Book streaming services shortened to BSS in figure, but not in the survey. Predicting future use of book streaming services among non-users.

Hierarchical multiple regression was used to test the hypotheses (Table 4). In the first step, age was entered as a predictive variable. In the second step, we included perceived convenience value, perceived price value and emotional attachment to printed books. The set-up hence enables us to assess the ability of these constructs to predict behavioural intention, after controlling for the influence of age.

In model 1, age accounts for $4 \%$ of the variation in behavioural intention $\left(R^{2}=0.004\right.$; adjusted $R^{2}$ $=0.003$ ). In model $2, R^{2}$ increases by $28 \%$, making $R^{2} .281$ (adjusted $R^{2}=0.278$ ). This change in $\mathrm{R} 2$ is significant with an F-statistic of $81.52(p<0.001)$.

Perceived convenience value (H1) explains the largest variance in behavioural intention $(\beta=0.35$, $p<0.001)$, followed by perceived price value (H4) $(\beta=0.28, p<0.001)$, and a weak negative effect of 
Table 3. Correlation coefficients.

\begin{tabular}{lccccc}
\hline & Age & Gender & PCV & PPV & EA \\
\hline Age & $\mathrm{I}$ & & & & \\
Gender & 0.039 & $\mathrm{I}$ & & & \\
Perceived conv. value & $-0.160^{* *}$ & $-0.124^{* *}$ & $\mathrm{I}$ & & \\
Perceived price value & $-0.094^{* *}$ & $-0.100^{* *}$ & $0.349 * *$ & $\mathrm{I}$ & \\
Emotional attachment & $0.063^{*}$ & -0.055 & $-0.265^{* *}$ & $-0.097^{* *}$ & $\mathrm{I}$ \\
Behavioural intention & $-0.098^{* *}$ & -0.028 & $0.448^{* *}$ & $0.426 * *$ & $-0.214^{* *}$ \\
\hline
\end{tabular}

**Correlation is significant at the $0.0 \mathrm{I}$ level (2-tailed). *Correlation is significant at the 0.05 -level (2-tailed). PCV $=$ Perceived convenience value.

PPV, Perceived price value; EA, Emotional attachment to printed books; Gender: I= male; $0=$ female.

Table 4. Hierarchical multiple regression on hypotheses.

\begin{tabular}{llllr}
\hline & \multicolumn{2}{l}{ Behavioural intention } & \\
\cline { 2 - 5 } & $b$ & SE B & $\beta$ & p-value \\
\hline Model I & & & & \\
$\quad$ Constant & 2.34 & 0.09 & & 0.054 \\
Age & -0.003 & 0.002 & -0.07 & \\
Model 2 & & & & \\
Constant & 0.49 & 0.19 & 0.04 & $<0.001$ \\
Age & 0.002 & 0.001 & 0.35 & $<0.001$ \\
Perceived convenience value & 0.35 & 0.03 & 0.28 & 0.007 \\
Perceived price value & 0.26 & 0.03 & -0.08 & \\
Emotional attachment & -0.07 & 0.03 & & \\
\hline
\end{tabular}

$R^{2}=0.004$ for Model I $(p=0.05) ; \Delta R^{2}=0.277$ for Model $2(p<0.00 I)$

emotional attachment to printed books $(\mathrm{H} 5)(\beta=-0.08, p<0.05)$. Since effort expectancy and social influence did not load as separate constructs (see Table 2), H2 and H3 could not be tested. We will return to these results and consider their implications in the subsequent discussion.

As our study is based on a random population sample, we also test the null hypothesis that the population partial regression weight is zero against the alternative that it is different from zero. We do this by examining the t-statistics for each predictor constructs, controlled for the other constructs (Hayes, 2009, p. 337-338). Each predictive construct remained statistically significant also after controlling for the other constructs. For perceived convenience value, $\mathrm{b}=0.34$, partial $r=0.35, t(835)=10.65, p<$ 0.001 . For perceived price value, $b=0.24$, partial $r=0.29, t(835)=8.73, p<0.001$. And finally for emotional attachment, $b=-0.07$, partial $r=-0.095, t(835)=-2.75, p<0.001$.

\section{Discussion}

Our first research question concerned who early adopters of book streaming services are, and what characterizes their use and experience. Results show that users are younger and more educated, and that book streaming services are more popular among women than men. Using education as a proxy 
for social status, diffusion of book streaming services hence to some extent follows Rogers (2003) characteristics of early adopters. Yet, it is notable that book streaming services show a different gender-uptake compared to what is common for e-books and new technologies more generally (Bergström and Höglund, 2020; Wallin and Nolin, 2020).

Comparisons of minutes spent consuming books (although highly skewed) across formats, suggest that reading/streaming is not an either/or option for book-streamers, supporting Read et al. (2011) finding that choice of format is not a binary option. Rather, for book-streamers, different formats likely fit different situations. Relatedly, the high shares of users agreeing with the convenience value items indicate that on-demand access to audiobooks allows for flexible ways of consuming books: having a large library of books available at times when reading is not an option (e.g. driving, walking, doing everyday chores). At other times, reading printed books is still the preferred option, and even among book-streamers, a relatively large share reports to agree with emotional attachment items for printed books. Book-streamers additionally spend significantly more time reading e-books compared to non-users, which might also reflect changing between streaming formats (listening and reading). Care should be taken not to compare users and non-users in terms of minutes consuming books. Non-users likely include a majority of users who in general do not read books for leisure, whereas book-streamers likely include a larger share of book-lovers.

With our second research question, we investigated what may predict future use of book streaming services among non-users. We included predictive constructs from technology acceptance and use theory, and adapted these to the case of book streaming services, ending up with a model where we predicted behavioural intention as an outcome of perceived convenience value (H1), perceived effort expectancy $(\mathrm{H} 2)$, social influence (H3), perceived price value (H4) and emotional value (H5). We additionally included gender and age as predictor variables. In the factor analysis, effort expectancy items loaded on the same factor as convenience value items; and social influence items loaded on the same factor as behavioural intention. H2 and H3 were hence not tested. The remaining hypotheses were supported, with convenience value explaining the largest variation in behavioural intention, followed by price value, and a weak negative effect of emotional attachment to printed books. The lacking effects of gender and age are noteworthy given the demographic differences between book-streamers and non-users. That is, whereas book-streamers are younger than non-users, age does not predict intention to start using book streaming services. Likewise, while a larger share of women uses book streaming services compared to men, gender does not predict future intentions of use. Leisure-time reading is much more common among women than men in Norway (Schiro, 2020), and similar gender differences are found in comparable countries (Bergström and Höglund, 2020). Hence, when gender does not predict intention to start using subscription-based audiobook services, this could signal how reading by listening may counterbalance reading as a traditionally gendered activity (see also Wallin and Nolin, 2020).

The results will next be discussed in three steps focusing on the contributions and limitations of this study. We first explicate how book streaming services are fundamentally different from printed books and e-books. Second, we turn to a discussion of the potential disrupting role of book streaming services. Third, we point to how this study validates the technology acceptance and use theory as applied to new consumer services, but we also attend to some core limitations of the theory regarding the specific characteristics of technologies and users.

First, previous studies have investigated use and non-use of e-books, but few have investigated the adoption of book streaming services. Several studies have pointed to the limited adoption of e-books, largely explained by emotional attachment to printed books (Antón et al., 2017; Bergström and Höglund, 2020; Helm et al., 2018; Read et al., 2011; Shim et al., 2016). Other studies have found support for the importance of ease of use/effort expectancy and perceived usefulness/ 
performance expectancy on intention to start using e-books (Lee, 2013; Read et al., 2011). However, book streaming services differ from purchasing e-books, and book-streamers pay for access and increased flexibility in modes of consuming books. This is reflected in how performance expectancy in this study is re-conceptualized as perceived convenience value; which is the most important construct for predicting intention to start using book streaming services. Moreover, as book streaming services provide access to books, rather than ownership through purchase, we might initially find the relatively weak association between emotional attachment and behavioural intention surprising (cf. Helm et al., 2018). However, book streaming, with listening as the most prevalent mode of consumption, has a different appeal and function compared to e-books and even printed books (Wallin and Nolin, 2020). Consequently, and compared to e-books, book streaming may have even more of a complementary rather than displacing function relative to printed books (cf. Bergström and Höglund, 2020; Read et al., 2011). A subsequent question is whether book streaming services as flexible and largely listening-mode services (that we argue do not explicitly compete with the multisensory experience of reading printed books) are worth the price. In the literature on e-book adoption, surprisingly few have included price value as a factor (for exceptions, see Helm et al., 2018; Loebbecke, 2010). Our results suggest that price value, conceptualized as the tradeoff between perceived benefits and monetary costs (Venkatesh et al., 2012), is an important construct for predicting intention to start using book streaming services.

Second, this study does not suggest that book streaming will replace printed books as the most prevalent mode of reading. While we expect number of book-streamers to continue increasing, it will likely plateau before reaching the majority of leisure-time book-readers. In Rogers (2003) terminology, book streaming might well have reached the 'take off' stage, yet we expect the increase in adopter distribution to be modest. Current non-users on average score low on behavioural intention $(M=2.1)$ and perceived price value $(M=2.6)$ (see Table 2), which in itself hints at limited potential for continued growth in number of book-streamers. A caveat in our reasoning here is relying too much on respondents' self-reported intentions on a type of service they have not actually experienced themselves. Yet, if compared to how music streaming has by and large replaced purchases of music in physical and digital formats (IFPI, 2019), the domain of books is different. Music-listening has always relied on music being technologically mediated: whether music comes in the form of a vinyl-album, CD, a digitally purchased file or a streamed file does not make much of a difference for the listening experience. While the printed book can certainly be considered a technology, for readers, the leap from print to digital formats is much more substantial. At this point it is worth reminding that emotional attachment to printed books only has a limited negative effect on intention to start using book streaming services, suggesting that book streaming appeals to broader segments than e-books. A pivotal question is whether book streaming services might also appeal to broader, or different, segments than printed books. If so, a third trajectory emerges that neither concerns complementing nor displacing existing reading habits, but rather creating reading habits where none previously existed.

Third, we have adapted the technology acceptance and use theory to the context of book streaming services. Constructs and adhering items have been defined and operationalized in ways that fit book streaming services, including adding emotional attachment to printed books as a predictive construct. We have as such not stayed true to the theory, and instead attempted to capture the appeal (convenience value) and barriers (emotional attachment) as related to book streaming as the object of study. Our model accounts for a modest $28 \%$ of the variation in behavioural intention, which is clearly inferior to the full UTAUT-model as tested for other technologies (Venkatesh et al., 2003, 2012). Future research on book streaming formats might benefit from staying truer to the UTAUT-model. 
However, some of the limitations of this study stem from how the general technology acceptance model, even in its extended version (Venkatesh et al., 2012), does not capture the characteristics of specific technologies, nor does it include consumer-characteristics that might explain acceptance. More specifically, future studies might consider examining how listening to audiobooks corresponds to hedonic, utilitarian and eudaimonic reading motives (Oliver and Raney, 2011; Stokmans, 1999). Whereas the convenience value construct used in this study at least partially appears to tap into the experiential dimensions of reading by listening, this mode of reading cannot be reduced to multi-tasking (e.g. reading while doing chores) and utilitarian efficiency. We also encourage future studies to consider how book streaming services might appeal differently to people depending on their reader-profiles. This study was not designed to investigate intentions to use book streaming services as potentially associated with established practices of reading (and purchasing) books (or lack of such practices). A question that we cannot address with this study is hence whether book streaming services primarily appeal to 'book-lovers' or whether they might turn non-readers into readers. Investigating such questions might modify our argument that book streaming has a complementary rather than displacing function relative to printed books. That is, book streaming services may have a complementary function for book-readers, but given their listening-mode appeal, these services may also attract those who do not regularly read books. Non-readers account for a large share of the population: Public statistics shows that about $42 \%$ of Norwegians read books during an average week (not counting reading for school, studies or work) (Schiro, 2020: 87). If book streaming services 'convert' non-readers into readers, then these services could potentially represent a benevolent disruption for the publishing industry.

\section{Conclusion}

The results of this study could, on the one hand, be interpreted to corroborate our introductory observation: that the printed book and traditional ways of reading books still remain resilient to change. A relatively modest share of non-users reports intentions to start using book streaming services. Compared to how the streaming model has disrupted how consumers listen to music, and how audiences increasingly also turn to streaming services for television content, books appear to be a different matter. While streaming services will likely be adopted by a considerable share of bookreaders, the replacement of printed books for digital formats, including streaming services, is an unlikely scenario. Even among book-streamers, reading printed books remains important. We might consequently conclude that for the majority of book-readers, nothing fully compares and competes with or replaces printed books. On the other hand, this study suggests that streaming services for books have a broader appeal compared to e-books. And more importantly, by expanding and complementing what a reading experience can be, these services might be considered to have a different appeal than printed books. The convenience of having on-demand access to a large library of audiobooks available at anytime facilitates a different reading experience. We might thus propose that people turn to book streaming services exactly because on-demand listening to audiobooks does not compare to reading printed books. A crucial question for future research is therefore whether book streaming services might attract those who traditionally do not read for leisure.

\section{Declaration of conflicting interests}

The author(s) declared no potential conflicts of interest with respect to the research, authorship, and/or publication of this article. 


\section{ORCID iDs}

Linn-Birgit Kristensen (D) https://orcid.org/0000-0001-6198-7062

Marika Lüders (D) https://orcid.org/0000-0002-5168-9712

\section{References}

Ajzen I (1991) The theory of planned behavior. Organizational Behavior and Human Decision Processes 50(2): 179-211.

Ajzen I (2002) Constructing a TPB Questionnaire: Conceptual and Methodological Considerations. Amherst: Working Paper. University of Massachusetts. Retrieved from: https://pdfs.semanticscholar.org/0574/ b20bd58130dd5a961fla2db10fd1fcbae95d.pdf.

Antón C, Camarero C and Rodríguez J (2017) Pleasure in the use of new technologies: the case of e-book readers. Online Information Review 41(2): 219-234. DOI: 10.1108/OIR-10-2015-0331.

Bergo S (2018) Det Er Klart at Strømming Er Enklere: Vårt Land. Retrieved from: https://reportasje.vl.no/ artikkel/559-det-er-klart-at-stromming-er-enklere.

Bergström A and Höglund L (2020) E-books: in the shadow of print. Convergence: The International Journal of Research Into New Media Technologies 26(4): 895-911. DOI: 10.1177/1354856518808936.

Collier EJ, Sherrell DL, Babakus E, et al. (2014) Understanding the differences of public and private selfservice technology. The Journal of Sexual Medicine 28(1): 60-70. DOI: 10.1108/JSM-04-2012-0071.

Davis FD (1989) Perceived Usefulness, Perceived Ease of Use, and User Acceptance of Information Technology. The Milbank Quarterly 13(3): 319. DOI: 10.2307/249008.

Davis FD, Bagozzi RP, and Warshaw PR (1992) Extrinsic and Intrinsic Motivation to Use Computers in the Workplace1. Journal of Applied Social Psychology 22(14): 1111-1132.

Den Norske Forleggerforening (2020) Bokmarkedet 2019 - Forleggerforeningens Bransjestatistikk: Report from Den Norske Forleggerforening. Available at: https://forleggerforeningen.no/wp-content/uploads/ 2020/06/Bransjestatistikk_2019_internet-v2.pdf (accessed 31 March 2021).

Dutton WH and Reisdorf BC (2019) Cultural divides and digital inequalities: attitudes shaping Internet and social media divides. Information, Communication \& Society 22(1): 18-38.

Hampton-Sosa W (2017) The impact of creativity and community facilitation on music streaming adoption and digital piracy. Computers in Human Behavior 69: 444-453.

Hargittai E (2002) Second-level digital divide: differences in people's online skills. First Monday 7(4).

Hargittai E, Piper AM, and Morris MR (2019) From internet access to internet skills: digital inequality among older adults. Universal Access in the Information Society 18(4): 881-890.

Hayes AF (2009) Statistical Methods for Communication Science. Routledge.

Hegnar M (2021) Dette er bokbransjens vekstmaskiner. Finansavisen, 27. Available at: https://finansavisen.no/ lordag/reportasje/2021/02/27/7632739/storytel-fabel-og-strawberry-publishing-rapporterer-om-kraftigvekst-i-omsetning-de-siste-arene-for-lydboker-og-stromming-av-boker (accessed 8 April 2021).

Helm SV, Ligon V, Stovall T, et al. (2018) Consumer interpretations of digital ownership in the book market. Electronic Markets 28(2): 177-189. DOI: 10.1007/s12525-018-0293-6.

IFPI (2019) Global Music Report 2019. Retrieved from: https://www.ifpi.org/news/IFPI-GLOBAL-MUSICREPORT-2019.

Kristensen LBK and Solvoll M (2019) Digital payments for a digital generation. Nagoya Journal of Medical Science 1(1): 125-136.

Lee S (2013) An integrated adoption model for e-books in a mobile environment: evidence from South Korea. Telematics and Informatics 30(2): 165-176. 
Loebbecke C (2010) The Emergence of Ebooks: Just Another Media Industry Joining the Converging Digital World? an Explorative Study on User Preferences and Industry Structure Changes. TPRC. Retrieved from: https://ssrn.com/abstract=1986386.

Oliver MB and Raney AA (2011) Entertainment as Pleasurable and meaningful: identifying hedonic and eudaimonic motivations for entertainment consumption. Journal of Communication 61(5): 984-1004.

Oyedele A and Simpson PM (2018) Streaming apps: What consumers value. Journal of Retailing and Consumer Services 41: 296-304. DOI: 10.1016/j.jretconser.2017.04.006.

Read W, Robertson N, and McQuilken L (2011) A novel romance: the technology acceptance model with emotional attachment. Australasian Marketing Journal 19(4): 223-229.

Rogers EM (2003) Diffusion of Innovations. 5th ed. Free Press.

Schiro EC (2020) Norsk Mediebarometer 2019. Oslo: Statistics Norway.

Shim D, Kim JG, and Altmann J (2016) Identifying key drivers and bottlenecks in the adoption of E-book readers in Korea. Telematics and Informatics 33(3): 860-871. DOI: 10.1016/j.tele.2015.12.009.

Sinclair G and Tinson J (2017) Psychological ownership and music streaming consumption. Journal of Business Research 71: 1-9.

Stokmans MJW (1999) Reading attitude and its effect on leisure time reading. Poetics 26(4): 245-261.

Taherdoost H (2018) A review of technology acceptance and adoption models and theories. Procedia Manufacturing 22: 960-967. . DOI: 10.1016/j.promfg.2018.03.137.

Tefertiller A (2018) Media Substitution in cable cord-cutting: the adoption of web-streaming television. Journal of Broadcasting \& Electronic Media 62(3): 390-407.

Torres R, Johnson V, and Imhonde B (2014) The impact of content type and availability on ebook reader adoption. Journal of Computer Information Systems 54(4): 42-51. DOI: 10.1080/08874417.2014. 11645721.

van der Heijden H (2004) User Acceptance of Hedonic Information Systems. The Milbank Quarterly 28(4): 695-704.

Van Deursen A and Van Dijk J (2011) Internet skills and the digital divide. New Media \& Society 13(6): 893-911.

Van Deursen AJ and Van Dijk JA (2014) The digital divide shifts to differences in usage. New Media \& Society 16(3): 507-526.

Venkatesh V, Morris M., Davis GB, et al. (2003) User Acceptance of information technology: toward a unified view. The MIS Quarterly 27(3): 425-478.

Venkatesh V, Thong JYL, and Xu X (2012) Consumer acceptance and use of information technology: extending the unified theory of acceptance and use of technology. MIS Quarterly 36(1): 157-178.

Tattersall Wallin E and Nolin J (2020) Time to read: exploring the timespaces of subscription-based audiobooks. New Media \& Society 22(3): 470-488.

Williams MD, Slade EL. and Dwivedi YK (2014) Consumers' intentions to use e-readers. Journal of Computer Information Systems 54(2): 66-76.

Winship C and Radbill L (1994) Sampling weights and regression analysis. Sociological Methods \& Research 23(2): $230-257$. 